\title{
EFEK PEMBERIAN LATIHAN HOLD RELAX DAN PENGULURAN PASIF OTOT KUADRISEP TERHADAP PENINGKATAN LINGKUP GERAK FLEKSI SENDI LUTUT DAN PENURUNAN NYERI PADA PASIEN PASCA ORIF KARENA FRAKTUR FEMUR 1/3 BAWAH DAN TIBIA 1/3 ATAS
}

\author{
Yulianto Wahyono, Budi Utomo \\ Kementerian Kesehatan Politeknik Kesehatan Surakarta Jurusan Fisioterapi
}

\begin{abstract}
Fracture, Hold Relax, stretching Passive, LGS Knee And Pain. Handling fracture is divided into three stages, namely (1) returns the position of the bone, (2) the installation of immobilization and (3) returns a function (rehabilitation). To restore the position of the bones in the anatomical shape / reduction and installation imibilisasi, generally carried out operative measures. As a result of operative measures will cause swelling and pain. The pain that there will be increased when the $j$ oints around the fracture is moved. For protection, it will automatically happen increasing muscle tension (muscle spasm). That impact will be an increase in pain and decreased range of motion/ LGS. Postoperative problems can be minimized by measures such as physiotherapy exercises. The design of the study using two group pre test and post test design, hold group relax and passive stretching each 16 subjects, each treatment dose groups of 10 repetitions, three times a series of exercises given 2 times / day for 2 consecutive days. Conclusion: (1) exercise hold relax and stretching passive muscle quadriceps effect on pain reduction and improvement LGS knee flexion, (2) the exercise hold relax effect is better than stretching exercises passive muscle quadriceps against a decrease in pain and improvement LGS knee flexion in patients with post ORIF because the third femur fractures or fractures of the tibia below the upper third.
\end{abstract}

Keywords: Fracture, Hold Relax, stretching Passive, LGS And Knee Pain

Abstrak: Fraktur, Hold Relax, Penguluran Pasif, LGS Lutut Dan Nyeri.
Penanganan fraktur terbagi atas tiga tahap, yaitu (1) pengembalian posisi tulang, (2)
pemasangan immobilisasi dan (3) pengembalian fungs (rehabilitasi). Untuk
mengembalikan posisi tulang pada bentuk anatomisnya/reduksi dan pemasangan
imibilisasi, umumnya dilakukan tindakan operatif. Akibat tindakan operatif tersebut
akan menimbulkan pembengkakan dan nyeri. Rasa nyeri yang ada akan bertambah
bilamana sendi di sekitar perpatahan digerakan. Sebagai proteksi, maka secara otomatis
akan terjadi peningkatkan ketegangan otot (muscle spasm). Hal itu berdampak akan
terjadi peningkatan nyeri dan penurunan lingkup gerak sendi/LGS. Masalah pasca
operasi tersebut dapat diminimalkan dengan tindakan fisioterapi berupa latihan.
Rancangan penelitian menggunakan two group pre test and post test design, kelompok
hold relax dan penguluran pasif masing-masing 16 subyek, dosis perlakuan masing-
masing kelompok 10 kali pengulangan, 3 kali seri latihan diberikan 2 kali/hari selama 2
hari berturutan. Kesimpulan: (1) latihan hold relax maupun penguluran pasif otot
kuadrisep berpengaruh terhadap penurunan nyeri dan peningkatan LGS fleksi lutut, (2)
latihan hold relax berpengaruh lebih baik daripada latihan penguluran pasif otot 
kuadrisep terhadap penurunan nyeri dan peningkatan LGS fleksi lutut pada pasien pasca ORIF karena fraktur femur 1/3 bawah atau fraktur tibia 1/3 atas.

Kata Kunci : Fraktur, Hold Relax, Penguluran Pasif, LGS Lutut Dan Nyeri

\section{PENDAHULUAN}

Fraktur atau patah tulang merupakan bentuk gangguan kontinyuitas tulang yang disebabkan karena trauma langsung maupun tidak langsung. Penanganan fraktur terbagi atas tiga tahap, yaitu (1) pengembalian posisi tulang pada bentuk anatomisnya/ reduksi, mempertahankan posisi tulang untuk beberapa waktu/ immobilisasi dan (3) pengembalian fungsi (rehabilitasi) sehingga seorang penderita akan mampu beraktivitas kembali tanpa mendapatkan hambatan yang berarti (Appley, 1995). Namun, akibat tindakan operatif tetap akan menimbulkan masalah antara lain adanya pembengkakan dan nyeri. Rasa nyeri yang ada akan bertambah bilamana sendi di sekitar perpatahan digerakan. Sebagai proteksi, maka secara otomatis akan terjadi peningkatkan ketegangan otot (muscle spasm). Hal itu berdampak akan terjadi peningkatan nyeri dan penurunan lingkup gerak sendi (LGS), yang pada akhirnya terjadi gangguan fungsi (Appley, 1995).

Fisioterapis dengan berbagai modalitas terapi latihan dapat menurunkan nyeri dan meningkatkan LGS sehingga pasien dapat beraktivitas dan produktif kembali. Terapi latihan yang biasanya diberikan untuk meningkatkan LGS adalah terapi latihan konvensional misalnya penguluran secara pasif dan terapi latihan metode khusus misalnya hold relax (Kisner dan Lynn, 1996).

Penguluran pasif adalah metode untuk memperpanjang komponen kontraktil atau nonkontraktil dari unit musculotendinoeus dimana gaya yang diberikan dari luar dan diberikan secara manual (Kisner dan Lynn, 1996). Penguluran unit musculotendinoeus tersebut berakibat membangkitkan refleks regang atau refleks myotatik, sehingga menyebabkan peningkatan ketegangan (spasme) otot. Itulah sebabnya mengapa penguluran secara pasif biasanya didapatkan hasil penambahan LGS yang kurang maksimal (Basmajian, 1985).

Hold relax dengan kontraksi antagonis adalah suatu teknik menggunakan kontraksi isometrik yang optimal dari kelompok otot antagonis yang memendek, kemudian setelah melalui fase rileksasi, otot agonis dikontraksikan secara isotonik untuk mengulur otot antagonis yang spasme atau memendek (Basmajian, 1985). Tujuan kontraksi isometrik antagonis adalah untuk mendapatkan rileksasi yang optimal setelah otot bekerja secara optimal sehingga memutus reflek myotatic. Hal itu dikenal dengan teori autogenic inhibition (Basmajian, 1985).

Dari kedua teknik penguluran tersebut secara teori penguluran dengan hold relax didapat hasil yang lebih menguntungkan. Demikian pula dengan berbagai penelitian terdahulu, misalnya penelitian Munir (2009), yang menyimpulkan bahwa latihan dengan metode hold relax berpengaruh lebih baik untuk meningkatkan LGS lutut dibandingkan dengan penguluran pasif. Shankar dan Yogita (2010) di Gujarat India, mendapatkan hasil bahwa teknik hold relax lebih efektif untuk 
meningkatkan fleksibilitas otot, dari pada teknik pasif stretching. Demikian pula dengan hasil penelitian Tannigawa (2004), menunjukkan bahwa efek hold relax signifikan terhadap peningkatan LGS dan penurunan nyeri pada kekakuan sendi pergelangan kaki akibat cedera olah raga.

\section{METODE PENELITIAN}

Rancangan penelitian ini menggunakan two group pre test and post test design, kelompok I diberi perlakuan berupa latihan hold relax, sedangkan kelompok II diberi latihan penguluran pasif. Dosis perlakuan masing-masing kelompok adalah (1) frekuensi : 10 kali/seri, 3 seri/latihan, (2) durasi : 2 kali/hari selama 2 hari berturutan.

Subyek penelitian ini adalah seluruh pasien pasca ORIF karena fraktur femur $1 / 3$ bawah atau fraktur tibia $1 / 3$ atas yang telah dilakukan tindakan pemasangan internal immobilisasi di RSUI Kustati Surakarta, yang memenuhi kriteria inklusi sebagai berikut (1) fraktur tunggal tertutup, (2) pasca ORIF hari ke 2, (3) mampu berkomunikasi dengan baik. Jumlah subyek 32 orang 9masing-masing kelompok sejumlah 16 orang.

Alat ukur yang digunakan pada penelitian ini adalah (1) VAS untuk mengetahui derajat nyeri yang dirasakan subyek. Pengisiannya dengan cara subyek diminta menunjuk tingkat nyeri yang dialami pada suatu garis horisontal yang panjangnya $100 \mathrm{~mm}$, dimana 0 (ujung kiri) merupakan titik tidak ada rasa nyeri dan 100 (ujung kanan) menunjukkan nyeri hebat, (2) goniometer untuk mengukur LGS fleksi sendi lutut. Analisis data menggunakan uji regresi.

\section{HASIL PENELITIAN \\ Karakteristik Subyek}

Distribusi karakteristik subyek penelitian berdasarkan jenis kelamin pada kedua kelompok adalah sama, yaitu lakilaki 11 orang $(68,8 \%)$ dan perempuan 5 orang $(31,3 \%)$. Sedangkan karakteristik subyek penelitian berdasarkan rerata usia juga relatif sama, yakni kelompok I umur rata-rata 37,8 tahun (13-63 tahun) dan kelompok II rata-rata umur 40,3 tahun (12-71 tahun). Adapun karakteristik subyek penelitian berdasarkan jenis implant pada kedua kelompok juga relatif sama (tabel 1).

Tabel 1

Karakteristik Jenis Implan

\begin{tabular}{lcccc}
\hline \multirow{2}{*}{ Jenis Implan } & \multicolumn{2}{c}{ Kel. I } & \multicolumn{2}{c}{ Kel. II } \\
\cline { 2 - 5 } & org & $\%$ & Org & $\%$ \\
\hline plate \& screw & 8 & 50 & 11 & 68.75 \\
\hline $\begin{array}{l}\text { intra medulare } \\
\text { nail (IMN) }\end{array}$ & 7 & 43.75 & 4 & 25 \\
\hline nail & 1 & 6.25 & 1 & 6.25 \\
\hline
\end{tabular}

Keadaan awal rerata nyeri dan LGS

fleksi lutut pada kedua kelompok relative sama yakni (1) Nyeri, kelompok I rerata 6,5, kelompok II rerata 6,6. (2) LGS fleksi lutut, Kelompok I rerata $57,5^{\circ}$, kelompok II rerata 57,80 (tabel 2).

Tabel 2

Keadaan Awal Nyeri dan LGS Fleksi Lutut

\begin{tabular}{lcc}
\hline \multicolumn{1}{c}{ Karakteristik } & Pok I & Pok II \\
\hline 1.Nyeri & & \\
- Rerata & 6,5 & 6,6 \\
- Range & $5-8$ & $5-8$ \\
- SD & 0,96 & 0,95 \\
\hline 2. LGS & & \\
- Rerata & 57,5 & 57,8 \\
- Range & $15-80$ & $15-80$ \\
- SD & 17,1 & 17,3 \\
\hline
\end{tabular}




\section{Hasil Uji Beda}

Uji beda nyeri sebelum dan setelah perlakuan pada kelompok I menggunakan uji Wilcoxon, diperoleh nilai $\mathrm{p}=0,000(<$ 0,05). Hal itu menunjukkan bahwa terdapat perbedaan nyeri yang bermakna antara sebelum dan setelah perlakuan. Sehingga dapat disimpulkan bahwa hold relax berpengaruh terhadap penurunan nyeri.

Uji beda LGS fleksi sendi lutut sebelum dan setelah perlakuan pada kelompok I menggunakan uji Wilcoxon, diperoleh nilai $\mathrm{p}=0,000(\mathrm{p}<0,05)$. Hal ini menunjukkan bahwa terdapat perbedaan LGS fleksi sendi lutut yang bermakna antara sebelum perlakuan dan setelah perlakuan. Sehingga dapat disimpulkan bahwa hold relax berpengaruh terhadap peningkatan LGS fleksi lutut.

Uji beda nyeri sebelum dan setelah perlakuan pada kelompok II menggunakan uji Wilcoxon, diperoleh nilai $\mathrm{p}=0,000(<$ 0,05). Hal itu menunjukkan bahwa terdapat perbedaan nyeri yang bermakna antara sebelum dan setelah perlakuan. Sehingga dapat disimpulkan bahwa penguluran pasif berpengaruh terhadap penurunan nyeri.

Uji beda LGS fleksi sendi lutut sebelum dan setelah perlakuan pada kelompok II menggunakan uji Wilcoxon, diperoleh nilai $\mathrm{p}=0,000(\mathrm{p}<0,05)$. Hal ini menunjukkan bahwa terdapat perbedaan LGS fleksi sendi lutut yang bermakna antara sebelum perlakuan dan setelah perlakuan. Sehingga dapat disimpulkan bahwa penguluran pasif berpengaruh terhadap peningkatan LGS fleksi lutut.

Uji beda nyeri setelah perlakuan antara kelompok I dengan kelompok II menggunakan uji Mann-Whitney didapat nilai $\mathrm{p}=0,017(\mathrm{p}<0,05)$. Sedangkan hasil uji beda LGS fleksi sendi lutut menggunakan uji Mann-Whitney diperoleh nilai $\mathrm{p}=0,023(\mathrm{p}<0,05)$. Hal ini berarti ada perbedaan nyeri dan LGS fleksi sendi lutut setelah perlakuan antara kelompok I dengan kelompok II.

Untuk mengetahui mana yang lebih baik antara hold relax dan penguluran pasif, maka digunakan selisih rerata nyeri dan LGS fleksi sendi lutut pada kelompok I dan kelompok II. Selisih nyeri sebelum dan sesudah perlakuan pada kelompok I adalah 4,562 dan kelompok II 4,06 (tabel 5.4). Perubahan nyeri pada kelompok I lebih banyak daripada kelompok II sehingga dapat disimpulkan bahwa pengaruh penurunan nyeri pada hold relax lebih baik dari penguluran pasif.

Sedangkan selisih LGS fleksi sendi lutut sebelum dan sesudah perlakuan pada kelompok I adalah $41,2^{\circ}$ dan kelompok II sebesar $31,57^{\circ}$ (tabel 3), berarti peningkatan LGS fleksi sendi lutut pada kelompok I lebih banyak daripada kelompok II. Sehingga dapat disimpulkan bahwa pengaruh peningkatan LGS sendi lutut pada hold relax lebih baik dari penguluran pasif.

Tabel 3

\section{Selisih Nyeri dan LGS Fleksi Sendi} Lutut

\begin{tabular}{lcc}
\hline \multicolumn{1}{c}{ Data } & Pok I & Pok II \\
\hline 1. Nyeri & & \\
- Sebelum & 6,50 & 6,62 \\
- Setelah & 1,93 & 2,56 \\
- Selisih & 4,56 & 4,06 \\
\hline 2. LGS & & \\
- Sebelum & 57,50 & 57,80 \\
- Setelah & 98,75 & 89,37 \\
- Selisih & 41,20 & 31,57 \\
\hline
\end{tabular}




\section{PEMBAHASAN}

Hasil penelitian ini sesuai dengan penelitian yang dilakukan oleh Shankar dan Yogita (2010), dengan hasil bahwa untuk meningkatkan fleksibilitas otot hamstring, teknik hold relax lebih baik dibanding teknik terapi latihan penguluran pasif, (2) Munir (2009), yang menyimpulkan bahwa terapi hold relax lebih baik hasilnya untuk menambah LGS pada persendian leher dibanding teknik penguluran pasif dengan penahanan.

Pengaruh hold relax yang lebih baik dibanding penguluran pasif terhadap peningkatan LGS fleksi sendi lutut tersebut sesuai pula dengan mekanisme yang terjadi pada muscle spindle organs (MSO) dan golgi tendo organs (GTO). MSO sangat sensitif terhadap perubahan panjang (length) otot, yang mana ketika otot diulur responnya berupa mempertahankan panjang (tonic response) untuk memelihara posisi / posture atau mengubah panjang (phasic response) saat bergerak. Pergerakan aktif maupun pasif dapat terjadi bilamana otot antagonis rilek/ kendor. Rilek atau kendornya otot antagonis tersebut sangat tergantung pada ada tidaknya stimulus pada MSO-nya. Bilamana terjadi kontraksi yang tidak mengakibatkan bertambah panjangnya otot, maka MSO tidak terstimulus. Sebaliknya, bilamana ada kontraksi yang mengakibatkan bertambah panjangnya otot, maka MSO terstimulus sehingga antagonis merespon dengan meningkatkan tonusnya untuk mempertahankan panjang otot tersebut. Hold relax merupakan teknik penguluran yang diawali dengan kontraksi isometrik otot antagonis. Kontraksi isometrik berarti tidak terjadi perubahan panjang otot, sehingga tidak menstimulus MSO otot antagonis, yang pada akhirnya pergerakan ke arah agonis menjadi lebih mudah dan lebih luas. Lain halnya dengan penguluran pasif yang langsung berdampak pada peningkatan panjang otot antagonis, sehingga meningkatkan ketegangan otot antagonis yang pada akhirnya menghambat pergerakan ke arah agonis.

$$
\text { Golgi tendo organs (GTO) }
$$

merupakan reseptor yang ada di antara tendo otot dan serabut otot yang berfungsi membangkitkan inhibitory (hambatan) kekuatan impuls motorik yg menuju otot, sehingga mengurangi kekuatan kontraksi otot. GTO distimulasi oleh adanya ketegangan yang dihasilkan oleh serabut otot. Bilamana GTO terstimulus maka GTO akan melepaskan impuls yang diteruskan ke medulla spinalis. Di medulla spinalis, impuls GTO akan membangkitkan mekanisme inhibitory sehingga akan menghambat kekuatan impulse motorik yg menuju otot. Teknik hold relax diawali dengan kontraksi isometrik otot antagonis. Dengan adanya kontraksi otot antagonis akan berdampak terstimulusnya GTO sehingga membangkitkan mekanisme inhibitory, akibatnya menghambat kekuatan impuls motorik yg menuju otot antagonis. Penurunan impuls motorik pada otot antagonis tersebut berdampak melemahnya kontraksi otot antagonis sehingga hambatan kinerja otot agonis menjadi turun, akibatnya gerakan ke agonis menjadi lebih mudah dan lebih luas. Di samping itu, penurunan kontraksi antagonis berarti penurunan ketegangan otot sehingga stimulus pada nociseptor (organ penerima rangsang nyeri) juga menurun, akibatnya tidak membangkitkan nyeri. 


\section{KESIMPULAN DAN SARAN}

Kesimpulan (1) latihan hold relax maupun latihan penguluran pasif otot kuadrisep berpengaruh terhadap penurunan nyeri dan peningkatan LGS fleksi lutut, (2) latihan hold relax berpengaruh lebih baik daripada latihan penguluran pasif otot kuadrisep terhadap penurunan nyeri dan peningkatan LGS fleksi lutut.

Disarankan agar dilakukan penelitian lanjutan dengan mempertimbangkan (1) bekerja sama dengan dokter bedah yang menangani subyek untuk dapat menggunakan obat anti nyeri dan anti inflamasi yang sama merek dan dosisnya, (2) bekerjasama dengan perawat bangsal agar dapat mengendalikan aktifitas subyek di luar perlakuan.

\section{DAFTAR RUJUKAN}

Appley, G. A., dan Solomon, 1995; Orthopedi and Fraktur Sistem Appley; edisi ketujuh; Widya Medika. Jakarta.

Basmajian, J. V., 1985; Therapeutic Exercise; 3rd Edition; The William and Wilkins Baltimore. Ontario.

Kisner, C., dan Lynn, C., 1996; Theurapetic Exercise Foundation and Techniques; 3rd edition, F.A Davis Company. Philadelphia.

Munir, R., 2009; Perbandingan Hold Relax dengan Strain Counter Strain (SCS) Terhadap Penambahan Range Of Motion (ROM) dan Penurunan Nyeri Pada Gangguan Fungsi Cervikal; Diakses tanggal 18-2-2014 dari http://fisiocentre.blogspot.com/200 9/04/perbandingan-hold-relaxdenganstrain19.html.
Shankar G. dan Yogita, 2010; Efectiveness of passive stretching versus hold relax technique in fleksibility of hamstring muscle; OJHAS. Gujarat, India.

Tannigawa M., 2004; Comparasion of the Hold Relax Procedure and Passive Mobilization on Increasing Muscle Length. Tokyo 